\title{
Trends in community violence in England and Wales 1995-1998: an accident and emergency department perspective
}

\author{
V Sivarajasingam, J P Shepherd
}

\begin{abstract}
Objectives-To identify overall, seasonal, sex and age specific national trends in community violence from an accident and emergency (A\&E) department perspective.
\end{abstract}

Design and Setting-Prospective collection of national violence data from a stratified random sample of $33 \mathrm{~A} \& \mathrm{E}$ departments in England and Wales.

Methods-Data were analysed for the three years from May 1995 to April 1998. Time series statistical methods were used to detect trends among those aged 0-10, 11-17, 18-30, 31-50 and 51 + years.

Results-121 475 assaults were identified: 89533 (74\%) men sustained injury. Forty five per cent were aged 18-30. The significant trends were an increase in injured women and those aged 31-50. Significant seasonal trends were identified for both sexes and all age groups: peaks were found in July to September and troughs in February to April.

Conclusions-There was no overall significant change in levels of violence between 1995-1998 from an A\&E department perspective. Numbers of women injured and those aged 31-50 increased signifi-

Accepted for publication 30 October 2000

Violence Research Wales College of

Correspondence to: Professor J Shepherd, University of Medicine, Dental School, Heath Park, Cardiff

CF4 4XY, UK

(Oralsurgery@cardiff.ac.uk)

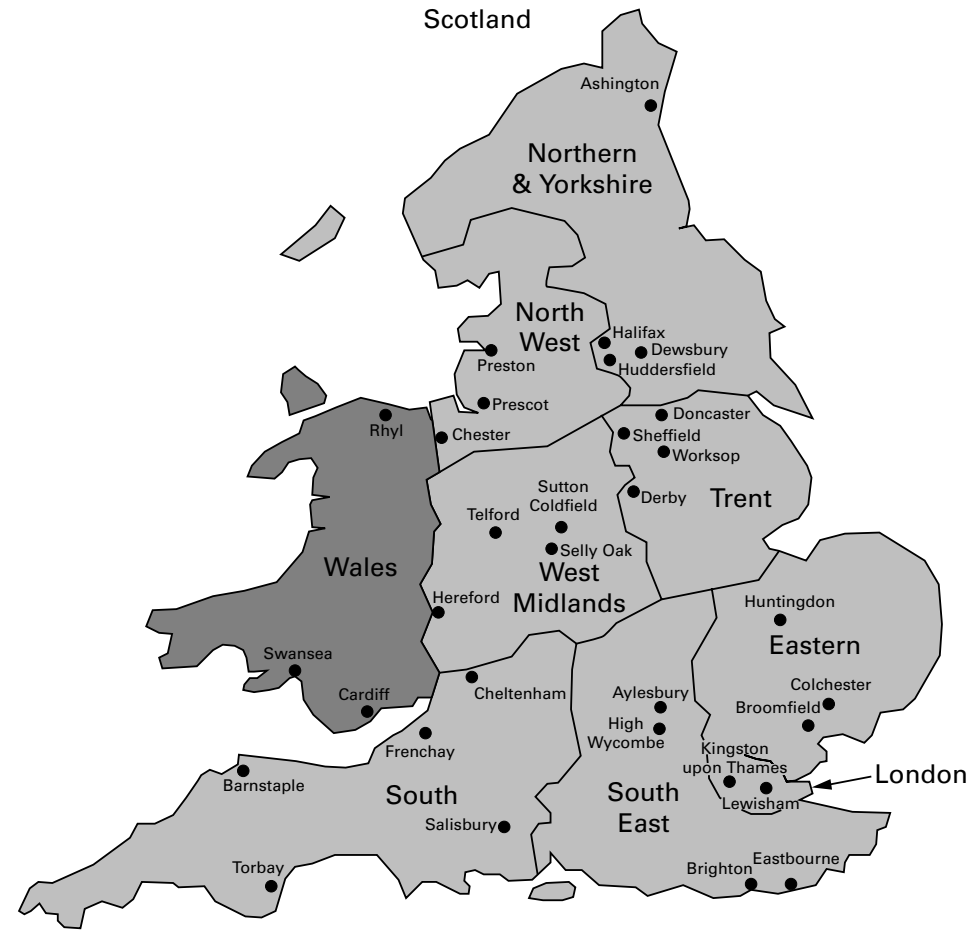

Figure 1 AEE departments and health regions. cantly. The incidence of injury sustained in community violence is biphasic: is highest during July to September and lowest during February to April. National $A \& E$ department violence surveillance provides a unique perspective.

(Emerg Med f 2001;18:105-109)

Keywords: assault; injury

Violence has become an important public health issue in UK. ${ }^{1}$ The consequences of violence: fatal and non-fatal injury and psychological harm are left to health professionals to treat. Violence research in the accident and emergency (A\&E) department has demonstrated the substantial extent to which offences that result in hospital treatment are not recorded by the police, ${ }^{2}$ that seriousness of injury is not a good predictor of outcome in the criminal justice system and that some categories: street and licensed premises violence, domestic violence and violence directed against men are less likely to be recorded by the police. $^{3}$

Currently, national data on violence in England and Wales come from two main sources, Police Crime Statistics and The British Crime Survey (BCS). Both have recognised shortcomings. In addition to undercounting many categories of violence, they do not provide objective information about injury. ${ }^{4}$ Importantly, threefold to 10 -fold more violent offences that occur in the community result in hospital treatment than are recorded by the police. ${ }^{6}$ Epidemiological studies are required to identify environments, circumstances and communities where the incidence of violence is higher or lower so that violence reduction programmes can be based on reliable evidence. Single centre studies have demonstrated the potential for local measurement of the effectiveness of violence reduction initiatives and local policing using A\&E derived injury data ${ }^{78}$ but no country has attempted a national systematic injury surveillance to facilitate this.

Health authorities are included in the Crime and Disorder Act (1998) ${ }^{9}$ as bodies with whom local authorities and the police must collaborate to audit and tackle crime. Evidence indicates that over $95 \%$ of those who are treated for injuries sustained in violence are treated in A\&E departments. ${ }^{7}$ In the UK, A\&E departments are therefore the principal potential source of violence data for Health Authorities. A\&E surveillance has become possible because of the development of information technology (IT) and the identification of 
Table 1 Software systems in use in the $33 A \mathcal{E} E$ departments

\begin{tabular}{ll}
\hline Software & $\begin{array}{l}\text { Number of } A \mathcal{E} E \\
\text { departments }\end{array}$ \\
\hline PAS & 15 \\
Footman and Walker & 9 \\
ReMaSS & 5 \\
MPI & 1 \\
CAMIS (Seamans) & 1 \\
EDS & 2 \\
Total & 33 \\
\hline
\end{tabular}

PAS = Patient Administration System $;$ MPI = Management Patient Information; CAMIS = Computer Assisted Management Information System; EDS = Electronic Data Set.

particular health workers who can reliably enter data (receptionists). The current A\&E modernisation programme focuses, among other objectives, on further development in IT and "front door" services. ${ }^{10}$

The aim of this study was to perform the first national $\mathrm{A} \& \mathrm{E}$ department-based survey of community violence in order to identify overall, seasonal, sex and age specific national trends.

\section{Methods}

England and Wales is served by 226 major ( 24 hour emergency cover with on site medical and nursing staff) A\&E departments in nine health regions (Northern \& Yorkshire, Trent, Northwest, West Midlands, Eastern, South West, South East, London, and Wales). Altogether, 109 A\&E departments had retrievable computer records for patients presenting since January 1995. A stratified random sample of 33 was selected from this pool, strata being defined as the health regions (fig 1). Several software packages had been installed (table 1) and the flow diagram (fig 2) demonstrates how data are captured in most $\mathrm{A} \& \mathrm{E}$ departments. Attendance dates and age and sex of patients who reported injury in assaults were analysed for the three year period; May 1995 to April 1998. Overall national trends were compared

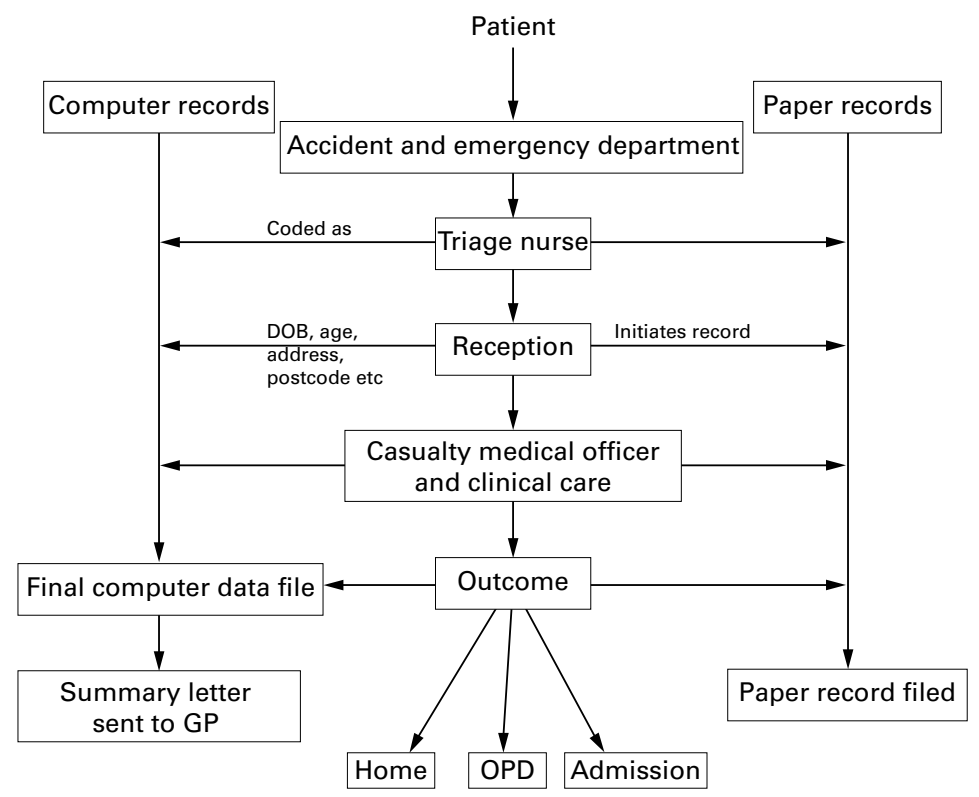

Figure 2 Flow of patients in most $A \mathcal{E} E$ departments. with those found in BCS and official Police Crime Statistics.

Time series statistical methods were used to look for linear trends in total violence and violence affecting men and women both at regional and national levels. ${ }^{11}$ Five age groups $(0-10,11-17,18-30,31-50,51+$ years $)$ were identified and separate time series analyses were carried out. Underlying trend was studied by taking the average of three consecutive months (that is, current, previous and following months) and comparing these moving averages to the average of the corresponding months in the previous year. Deterministic cycles of violence such as significant seasonal effects were also investigated. To investigate linear trends a simple model was used.

$Y_{t}=\alpha+\beta t+\varepsilon_{t}, t=1, \ldots, 36$

where $Y_{t}=$ number of assaults in month $t, \alpha=$ constant, $\beta=$ constant, $\varepsilon=$ error term.

The best such model was obtained by the least square regression method. For a seasonal effect a statistical model to detect seasonal patterns was fitted. As monthly data were the focus of interest the model is given by:

$$
\begin{aligned}
y_{t}=\alpha & +\beta t \\
& +\sum_{r=1}^{h}\left[a_{r} \sin \left(\frac{2 \pi}{p} t r\right)+b r \cos \left(\frac{2 \pi}{p} t r\right)\right] \\
& +\varepsilon_{t}, t=1, \ldots, 36
\end{aligned}
$$

where $\mathrm{h}$ is the largest integer not exceeding $\mathrm{p} / 2$. $\mathrm{P}$ is defined as the period of the model and $2 \pi / \mathrm{p}$ is defined as the frequency of the cyclic fluctuations. Sine and Cosine functions within square brackets indicate the seasonal model that fitted our data. Usually, in practice, a smaller $h$ suffices. The value of $h$ was chosen by looking at the lack of fits and in this study $h=4$.

\section{Results}

Altogether 109 A\&E departments in England and Wales satisfied the selection criteria. Table 2 shows the number of assaults recorded by health region and sex for the random sample of $33 \mathrm{~A} \& \mathrm{E}$ departments for the three year period. In all, 121475 assaults were recorded: $2.5 \%$ of all A\&E attendance ( $n=4842936)$. A total of $89533(74 \%)$ of the injured were men and 31942 (26\%) were women. Distribution of the injured is shown in figure 3. Highest rates of attendance were by those aged 18 to 30, followed by those aged 31 to 50, those aged 11 to 17 , those over 50 and those aged 0 to 10 . This order was maintained throughout the three year period.

LINEAR TREND FOR AGE AND SEX

Overall there was a steady increase in male and total attendance throughout the study period although this was not statistically significant. A $\mathrm{p}$ value of $<0.05$ was taken to be significant. Seven $(21 \%)$ of the 33 A\&E departments showed a significant increase in total attendance of those injured in assaults (Northern 
Table 2 Assault patient attendance by region and sex

\begin{tabular}{|c|c|c|c|c|c|c|c|c|c|}
\hline \multirow[b]{2}{*}{$A \mathcal{E} E$ departments by Health Region } & \multicolumn{3}{|c|}{ May 1995 to April 1996} & \multicolumn{3}{|c|}{ May 1996 to April 1997} & \multicolumn{3}{|c|}{ May 1997 to April 1998} \\
\hline & Male & Female & Total & Male & Female & Total & Male & Female & Total \\
\hline \multicolumn{10}{|l|}{ Trent } \\
\hline Bassetlaw (Worksop) & 598 & 258 & 856 & 538 & 224 & 782 & 519 & 260 & 779 \\
\hline Derby RI & 1756 & 595 & 2350 & 1790 & 626 & 2416 & 1914 & 708 & 2623 \\
\hline Doncaster RI & 1686 & 649 & 2335 & 1771 & 728 & 2499 & 1900 & 788 & 2688 \\
\hline Northern G (Sheffield) & 365 & 171 & 536 & 553 & 267 & 820 & 556 & 269 & 825 \\
\hline \multicolumn{10}{|l|}{ North West } \\
\hline Countess of Chester & 1654 & 479 & 2133 & 1519 & 436 & 1955 & 1522 & 473 & 1995 \\
\hline Royal Preston & 1213 & 409 & 1622 & 1118 & 367 & 1485 & 1022 & 382 & 1404 \\
\hline Whiston (Prescot) & 2017 & 729 & 2746 & 1961 & 761 & 2722 & 1911 & 729 & 2640 \\
\hline \multicolumn{10}{|l|}{ Northern and Yorkshire } \\
\hline Dewsbury & 659 & 301 & 960 & 623 & 302 & 925 & 682 & 288 & 970 \\
\hline Royal Halifax & 575 & 243 & 818 & 666 & 278 & 944 & 813 & 353 & 1166 \\
\hline Hartlepool G & 687 & 283 & 970 & 833 & 317 & 1150 & 683 & 311 & 994 \\
\hline Huddersfield RI & 499 & 193 & 692 & 488 & 184 & 672 & 506 & 222 & 728 \\
\hline \multirow{2}{*}{\multicolumn{10}{|c|}{ West Midlands }} \\
\hline & & & & & & & & & \\
\hline Good Hope (Sutton Coldfield) & 1116 & 348 & 1464 & 1240 & 415 & 1655 & 1166 & 375 & 1541 \\
\hline The General (Hereford) & 391 & 117 & 508 & 414 & 123 & 537 & 516 & 147 & 663 \\
\hline Princess Royal (Telford) & 454 & 184 & 638 & 517 & 221 & 738 & 525 & 222 & 747 \\
\hline Selly Oak (Birmingham) & 2113 & 725 & 2838 & 2092 & 706 & 2798 & 1775 & 657 & 2432 \\
\hline \multicolumn{10}{|l|}{ Eastern } \\
\hline Broomfield (Chelmsford) & 391 & 117 & 508 & 414 & 123 & 537 & 516 & 147 & 663 \\
\hline Colchester G & 515 & 214 & 729 & 537 & 203 & 740 & 489 & 195 & 684 \\
\hline Hinchingbrooke (Huntingdon) & 274 & 96 & 370 & 271 & 103 & 374 & 543 & 237 & 780 \\
\hline \multicolumn{10}{|l|}{ Southwest } \\
\hline Cheltenham G & 309 & 130 & 439 & 280 & 96 & 376 & 300 & 127 & 427 \\
\hline Frenchay & 712 & 187 & 899 & 373 & 135 & 508 & 432 & 187 & 619 \\
\hline Salisbury District & 280 & 84 & 364 & 276 & 81 & 357 & 271 & 84 & 355 \\
\hline Torbay & 621 & 210 & 831 & 661 & 218 & 879 & 607 & 229 & 836 \\
\hline North Devon District (Barnstaple) & 143 & 58 & 201 & 226 & 75 & 301 & 183 & 59 & 242 \\
\hline \multicolumn{10}{|l|}{ Southeast } \\
\hline Wycombe G (High Wycombe) & 653 & 250 & 903 & 701 & 235 & 936 & 698 & 228 & 926 \\
\hline District General (Eastbourne) & 604 & 190 & 794 & 623 & 173 & 796 & 556 & 193 & 749 \\
\hline Royal Sussex (Brighton) & 1368 & 391 & 1759 & 1504 & 431 & 1935 & 1469 & 382 & 1851 \\
\hline Stoke Mandeville (Aylesbury) & 606 & 221 & 827 & 622 & 190 & 812 & 577 & 217 & 794 \\
\hline \multicolumn{10}{|l|}{ London } \\
\hline Kingston & 796 & 246 & 1042 & 846 & 261 & 1107 & 1033 & 359 & 1392 \\
\hline Lewisham & 859 & 434 & 1293 & 828 & 422 & 1250 & 906 & 504 & 1410 \\
\hline \multicolumn{10}{|l|}{ Wales } \\
\hline Cardiff Royal & 2428 & 741 & 3169 & 2387 & 638 & 3025 & 2301 & 605 & 2906 \\
\hline Morriston (Swansea) & 1690 & 649 & 2339 & 1923 & 627 & 2550 & 1891 & 673 & 2564 \\
\hline Glan Clwyd (Rhyl) & 590 & 166 & 756 & 642 & 187 & 829 & 765 & 269 & 1034 \\
\hline Total & 29263 & 10352 & 39615 & 29943 & 10430 & 40273 & 30327 & 11160 & 41487 \\
\hline$\%$ & 73.9 & 26.1 & & 74.2 & 25.8 & & 73.1 & 26.9 & \\
\hline
\end{tabular}

General Sheffield; Royal Halifax; Hereford General; Broomfield, Chelmsford; Hinchingbrooke, Huntingdon; Kingston, Kingston upon Thames and Glan Clwyd, Rhyl) and four (12\%) showed a significant decrease (Countess of Chester; Royal Preston; Selly Oak; Birmingham and Cardiff Royal Infirmary). Overall there were significant increases in attendance of women and those aged 31 to 50 years. There

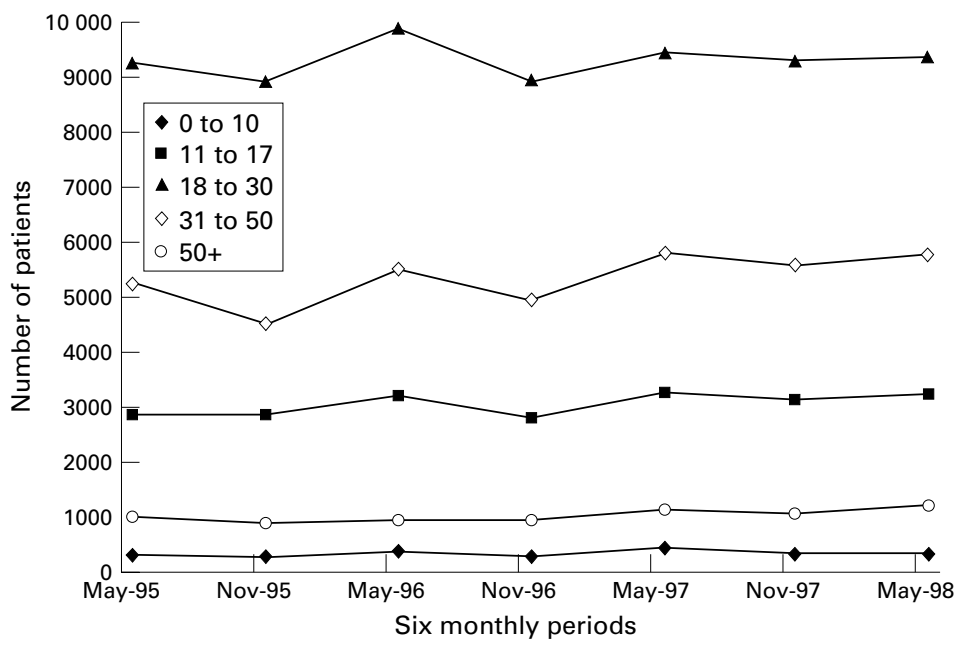

Figure 3 Attendance by age category for sequential six month periods: May 1995 to Apri11998. were small, non-significant increases for men and other age categories.

SEASONALITY FOR AGE AND SEX

Derby; Dewsbury; Princess Royal Hospital, Telford; and Royal Sussex Hospital, Brighton A\&E data demonstrated a significant seasonal component for male, female and total assault attendance with peaks during July to September and troughs during February to April. Seasonality was also significant for total attendance in Sheffield, Preston, Halifax, Huddersfield, Torbay, Aylesbury, Lewisham, Swansea and Rhyl with two peaks, during July to September and a second smaller peak during November to January, and a trough during February to April. Interestingly, this pattern of high attendance in the summer and low attendance in winter was repeated for total male and female populations in this sample (fig $4 \mathrm{~A}, 4 \mathrm{~B}$ ). The $18-30$ and $31-50$ year age groups were very similar in seasonality with increased A\&E attendance during July to September and decreased attendance during February to April with a smaller peak during November to January. Similarly, younger (0-10 and $11-17$ years) and older $(\geqslant 50$ years) groups showed consistent peaks during July to September and consistent troughs during January to April. The same seasonality was observed when Northern (Trent, Northwest, Northern \& 


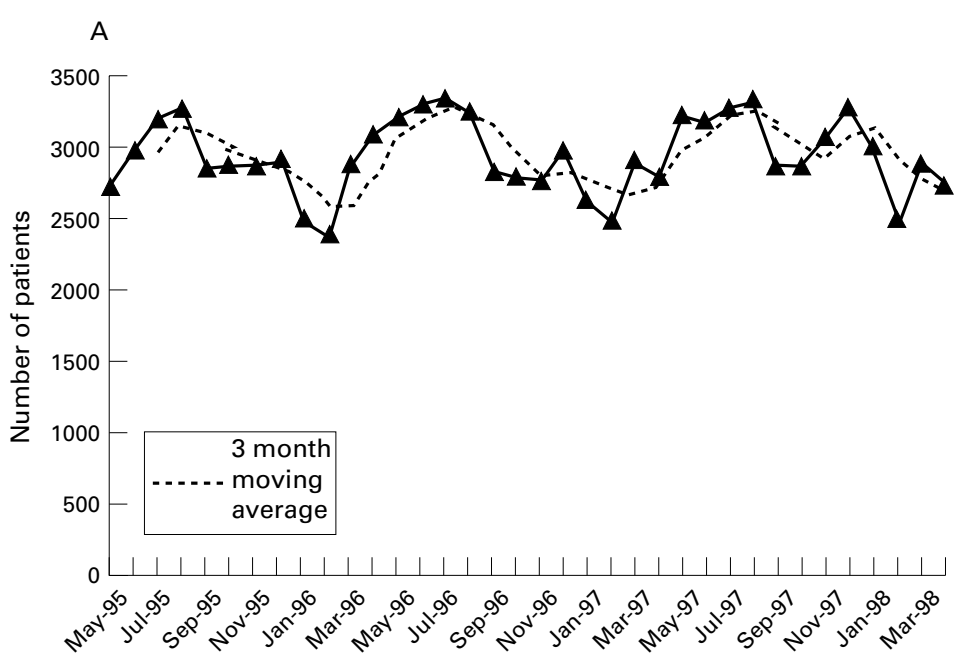

B

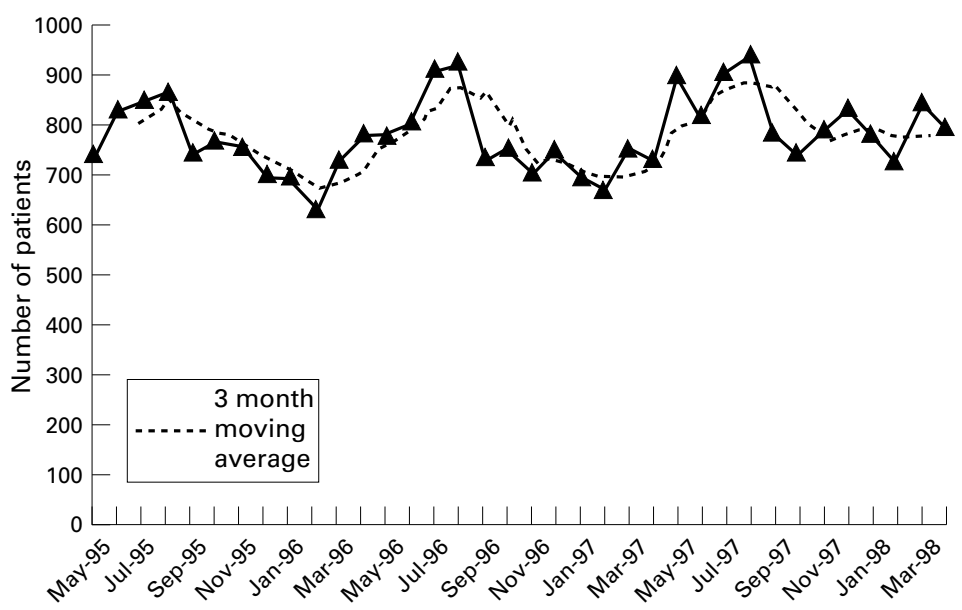

Figure 4 (A) Total attendance for men, and three month moving averages. (B) Total attendance for women and three month moving averages.

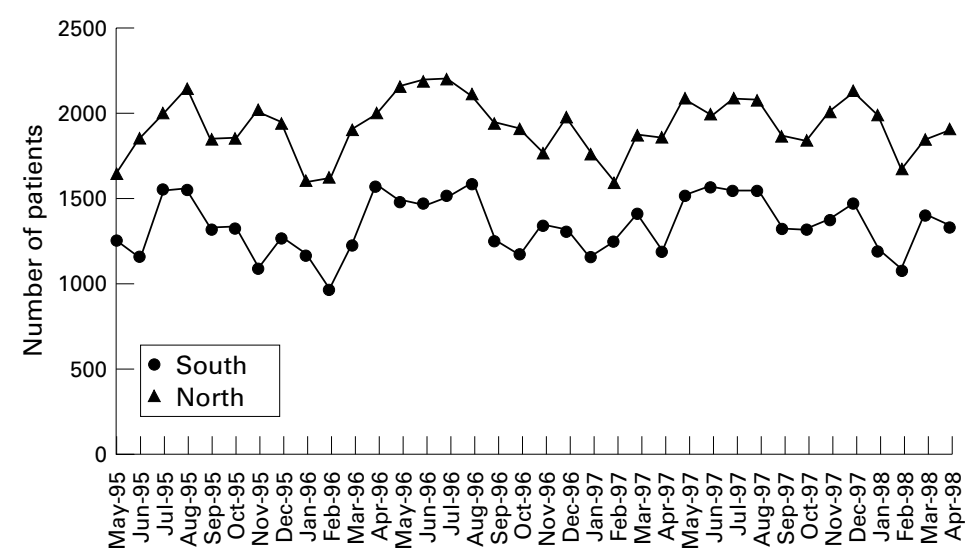

Figure 5 North to South comparison in seasonality.

Yorkshire, and West Midlands) and Southern (Eastern, Southwest, Southeast and London) data were compared (fig 5).

\section{Discussion}

The reasons why many violent offences are not reported to the police include inability to identify the assailant, fear of reprisals, an ongoing relationship with the assailant, a hostile attitude to the police and lack of facilities or encouragement to report in $\mathrm{A} \& \mathrm{E}$ departments. ${ }^{12}$ Furthermore, many violent offences that produce injury are not recorded or investigated when they have been reported: incidents may be classified as domestic rather than criminal or the injured may be found or alleged to have been responsible for what happened. ${ }^{13}$ Police records are also subject to changes in detection, reporting and recording practices. ${ }^{5}$

The BCS was initiated in response to increasing statistical and criminological evidence that crime statistics collected by the police did not reflect the true incidence of crime in England and Wales. Home office BCS interviewers ask one person over the age of 16 years in each of 11000 randomly selected households in England and Wales about their experience of crime in the past year. There have now been eight sweeps of the survey, at roughly two yearly intervals since the first BCS in 1981. The BCS is thought to undercount some categories of violence, including bar and street fights and domestic violence, and provides insufficient data for small area variations, seasonal trends and the effect of regional crime reduction initiatives or local police performance to be measured. ${ }^{45}$ As violence related injury varies with age and geographical setting, ${ }^{4}$ a clear understanding of the epidemiology of these injuries is essential for the development of primary, secondary and tertiary injury prevention.

An advantage of $\mathrm{A} \& \mathrm{E}$ data is that case identification depends not on the perception that a crime has been committed, but on the presence of injury deemed to require hospital treatment. All 33 hospitals included in this study had a minimum dataset (MDS) incorporated into their A\&E software that allowed capture of demographic data. Six different software packages were found to be in use (table 1). Trained receptionists and nurses enter patient details into the database. Some information was available about the circumstances of assault, such as locations, but incompleteness meant that reliable analysis of assault location was not possible. A mandatory assault MDS is therefore necessary: modifications to allow comparability of $\mathrm{A} \& \mathrm{E}$ and Home Office data, have been agreed with the authors of the BCS and have recently been published. ${ }^{10}$

It is important that future A\&E-based violence surveillance takes account of the effect of variations in access to A\&E departments. ${ }^{14}$ This means that minor injuries treatment centres need to be included. Equally importantly, measurement of trends must take account of changes in location of $A \& E$ services and reconfiguration of catchment populations.

In this study, the number of $\mathrm{A} \& \mathrm{E}$ attendees reporting injury in assault increased from 39615 during 95/96 to 41487 during 97/98: a rise of $1872(5 \%)$, which is less than the overall $10 \%$ (from 319675 to 352873 ) rise in violent crimes recorded by the police in England and Wales in the same period. ${ }^{5}$ The $1998 \mathrm{BCS}^{4}$ relating to crime in 1997 however, demonstrated a $17 \%$ decrease in violent offences compared with 1995. In the A\&E study reported here men and those aged $18-30$ years 
were most likely to be victims of violence and those over 50 were at lower risk. This is in agreement with the 1998 BCS. $^{4}$

It has been found that most assaults involving men occur in public places where "individual worth and identity are at stake" in confrontations with other men. ${ }^{7}$ Attendance of men reporting injury in assaults increased over the period 1995-8 but, interestingly, only attendance of women and those in the 31-50 age group increased significantly. As BCS data show a decrease in domestic violence of $16 \%$ between 1995 to $1997,{ }^{4}$ it is possible that violence involving women in public places increased. In a previous single centre study, rates of injury from street and licensed premises violence for women were higher than rates from domestic violence. ${ }^{7}$

Significant seasonality was evident in $69(26 \%)$ of the 264 time series analyses (for male, female, total and age categories for the 33 hospitals). Assaults affecting men, women and the $11-17,18-30$ and $31-50$ age groups peaked during the summer months between July to September and were at their lowest during February to April. It has been suggested in a single centre study that during the summer months, when larger numbers of people are out of doors, there is greater likelihood of violence. ${ }^{8}$ Interpretation of the significant seasonality in attendance shown by $0-10$ and $\geqslant 51$ year groups is difficult because of small numbers. Nevertheless, the finding that assault injury is a seasonal disorder seems particularly important.

Information about community violence collected in the $\mathrm{A} \& \mathrm{E}$ department is recorded very shortly after injury when the event is fresh in the minds of the injured and those who accompany them. A recently published questionnaire ${ }^{10}$ allows collection of data on particular Home Office categories of violence so that in future, trends in domestic, acquaintance and stranger violence can be studied. This should be incorporated into the $\mathrm{A} \& \mathrm{E}$ software throughout England and Wales. A\&E departments react to needs of patients who seek, or who are brought for treatment and are less likely to be prone to the reporting and recording biases known to affect police ascertainment of offences. This study shows that the collection of sound local and national epidemiological data on violence is achievable and that $A \& E$ departments have an important potential role in contributing to community safety, measuring the effectiveness of violence prevention initiatives and informing local police strategy. Importantly, this study was possible without additional expenditure in the A\&E departments.

The authors thank A\&E personnel for access to data and Home Office personnel for advice on BCS and police violence data and Dr Sanjit Sahu for statistical advice.

Funding: none.

Conflicts of interest: none.

1 Shepherd JP. Tackling violence. BMF 1998;316:879.

2 Shepherd JP, Scully C, Shapland M. Recording of violent offences by the police: an accident and emergency department perspective. Med Sci Law 1989;29:251-7.

3 Shepherd JP. Violence: the relation between seriousness of injury and outcome in the criminal justice system. $\mathcal{F}$ Accid Emerg Med 1997;14:204-8.

4 Mirrlees-Black C, Budd T, Partridge S, et al. The British Crime Survey: England and Wales. London: HMSO, 1998.

Povey D, Prime J, Taylor P. Notifiable offences: England and Povey D, Prime J, Taylor P. N
Wales. London: HMSO, 1997.

6 Sivarajasingam V, Shepherd JP. Effect of closed circuit television on urban violence. $\mathcal{F}$ Accid Emerg Med 1999;16: $255-7$

7 Shepherd JP, Ali MA, Hughes AO, et al. Trends in urban violence: a comparison of accident department and police records. F R Soc Med 1993;86:87-8.

8 Shepherd JP .Violent crime in Bristol. British fournal of Criminology 1990;30:289-304.

9 Crime and Disorder Act 1998. London: HMSO, 1998.

10 Goodwin V, Shepherd JP. The development of an assault questionnaire to allow $\mathrm{A} \& \mathrm{E}$ departments to contribute to Crime and Disorder Act Local Crime Audits. F Accid Emerg Med 2000; 17:1-2.

11 Diggle PJ. Time series: a biostatistical introduction: Oxford: Clarendon Press, 1990.

12 Shepherd JP, Lisles C. Towards multi-agency violence prevention and victim support. British fournal of Criminolgy 1998;38:351-70.

13 Clarkson C, Cretney A, Davis G, et al. Assaults: the relationship between seriousness, criminalisation and punishment. Criminal Law Review 1994;Jan:4-20.

14 Lyons RA, Lo SV, Heaven M. Injury surveillance in children - usefulness of a centralised database of accident and emergency attendances. Inj Prev 1995;1:173-6. 